Journal of Machine Engineering, 2020, Vol. 20, No. 1, 58-69

ISSN 1895-7595 (Print) ISSN 2391-8071 (Online)

Received: 13 September 2019 / Accepted: 16 January 2020 / Published online: 05 March 2020

machine tools, parallel kinematics, force measurement, sensor integration

\author{
Christian FRIEDRICH ${ }^{1 *}$ \\ Bernd KAUSCHINGER ${ }^{1}$ \\ Steffen IHLENFELDT ${ }^{1}$
}

\title{
STIFFNESS EVALUATION OF A HEXAPOD MACHINE TOOL WITH INTEGRATED FORCE SENSORS
}

\begin{abstract}
Today, in-process force measurement is required by many manufacturing applications, such as process monitoring, quality assurance, or adaptive process control. A very promising force measurement approach bases on sensorintegration into the machine structure and is particularly suitable for hexapod structures and kinematics, where it allows a measurement in 6 degrees of freedom. On the other hand, a sensor integration also affects the machine. Especially for strain-gauge-based force sensors, a stiffness reduction is predicted, as their measuring principle requires a deformation. The practical consequences of these influences are investigated in this contribution. In particular, this work presents extensive experimental studies of the stiffness change caused by sensor integration for a single hexapod strut as well as for the complete hexapod machine tool. The results are evaluated in comparison to compliances of other components, such as the kinematic joints, and to stiffness changes resulting from sensor-integration into the end-effector or the application of a commercial force/torque sensor at the endeffector. In conclusion, the studies support the approach of structure-integrated force measurement for parallel kinematics, as the stiffness loss is rather small in many cases.
\end{abstract}

\section{INTRODUCTION AND APPROACH}

Measurement and control of process forces allow increasing quality, productivity, and tool lifetime, reducing batch sizes, cycle times, and cost, and, finally, pave the way to new applications and processes, which overall coincides with the main goals in production. Therefore, many manufacturing applications require in-process force measurement, where, relating to the extended movability of modern machine tools, such as five-axis kinematics or hexapods, the measurement of spatial forces and moments in up to 6 degrees of freedom $(\mathrm{DoF})$ is requested in particular.

Earlier contributions present a new approach using hexapod-based structures with integrated sensors $[1,2]$. Hereby, six 1 DoF force sensors are integrated into rigid bar frameworks and kinematics and the measured forces are transformed to Cartesian forces and moments at the TCP by a control-integrated model. Compared to commercial $6 \mathrm{DoF}$

\footnotetext{
${ }^{1}$ TU Dresden, Institute of Mechatronic Engineering, Chair of Machine Tools Development and Adaptive Controls, Dresden, Germany

*E-mail: Christian.Friedrich@TU-Dresden.de https://doi.org/10.36897/jme/117786
} 
force/torque transducers (F/T sensors) that are mounted close to the tool centre point (TCP), the new measuring system does not reduce usable workspace, causes no restrictions to spindle mounting, and is also cost-efficient. Compared to force measurement based on drive current it is far more accurate and requires less modelling effort, since no non-linear and stochastic mechanical influences, such as friction, stick-slip effects, or elastic deformation of drive components interfere. Finally, the placement of cheap commercial single-axis force sensors is also advantageous when compared to individual strain-gauge-based solutions with specific design, such as spindles [1], end-effectors [2] or even the workpiece itself [3], that are costintensive and do not provide a spatial measurement in 6 DoF so far. A more detailed and still up-to-date view on the state of the art of machine-integrated force measurement solutions gives [4], which also discusses the use of rigid Stewart or hexapod structures as force sensors. Here, the most promising works with practical results are [5-12]. Still, all of these sensors are designed as pure (machine independent) measuring devices with static calibration. Neither a movement of the hexapod struts nor of the complete sensor as part of a machine is intended. Consequently, no kinematic or dynamic influences need to be respected.

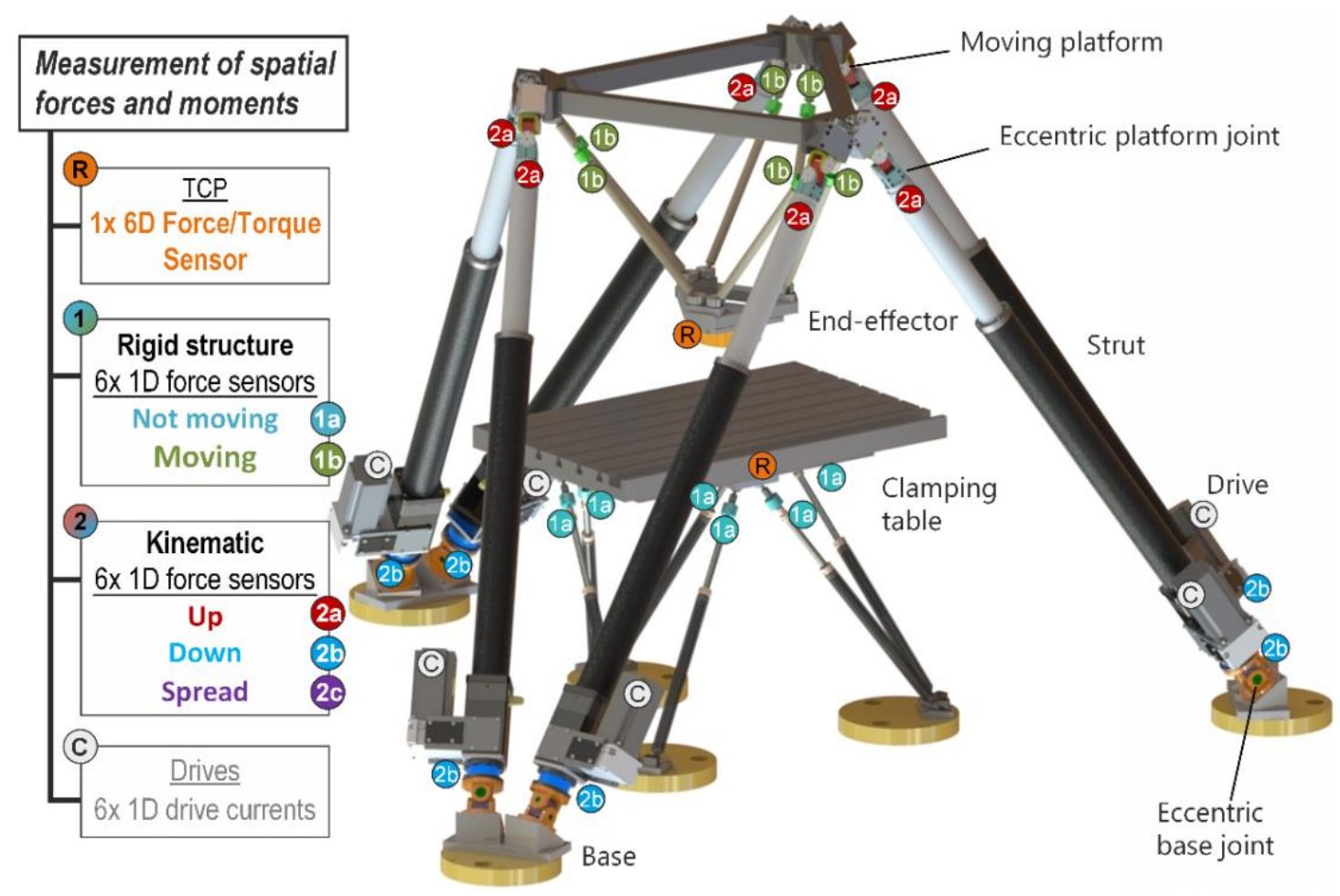

Fig. 1. Approach and variants of sensor placement in hexapod structures/kinematics: A clamping table (setup 1a: rigid, not moving), an end-effector (setup 1b: rigid, moving), a hexapod kinematic (setup 2x: sensors in the struts)

For the presented approach instead, an online model is essential. Depending on the exact sensor placement, different influences are included in a measurement model that accordingly requires parameters, such as masses, centres of gravity and inertias, as well as onlinecalculated machine states, such as positions, velocities, and accelerations, Fig. 1. Additional 
parameters can be introduced to include further influences concerning the sensibility of force sensors towards lateral forces, torques, elastic structure deformation, or temperature effects. A proof of concept for quasi-static measurements is presented in [13] that shows models, experimental results, and classification for all set-ups as well as parameter identification and influence analysis. A more detailed view on the end-effector including the dynamic model, dynamic and process force measurements discusses [4]. In conclusion, a precise spatial force measurement during machine movement with competitive characteristics compared to a commercial force/torque sensor can be realised in the whole workspace.

However, one major doubt on the integration of force sensors into machine structures refers to the loss of stiffness within the machine tool. As most force sensors contain strain gauges that, by definition, include deformation elements, this is a reasonable concern and needs to be investigated. Even thus, stiffness modelling and evaluation methods for serial and parallel kinematics have been studied for a long time [14-21], a specific evaluation on the effect of force sensor integration into parallel kinematic machines is missing in the literature to the best knowledge of the authors. Also, contributions discussing structureintegrated sensors in parallel kinematics itself are very rare, in contrast to the mentioned rigid Steward structures that are used as force sensor [4]. On that account, the new contributions of this paper are practical evaluations to the loss of stiffness by sensor integration for a single hexapod strut as well as for the complete hexapod machine tool in comparison to an optimisation of the kinematic joints that was focus of former works [22-24]. First, two single struts are evaluated on a test bench by applying load and measuring displacement using touch probes (Section 2). Second, the complete machine is assembled in different configurations and examined by the use of a double-ball-bar measuring system during the application of load (Section 3).

\section{AXIS STIFFNESS EVALUATION}

The hexapod machine tool FELIX consists of six identical struts that are constructed as shown in Fig. 2. For every strut, a ball screw drive, which is powered by a servomotor via a belt drive, creates an active linear movement and allows passive rotation. To reach a total DoF of six, two universal joints are mounted at the base and the top of the axis, respectively, with two rotational DoF each. A force sensor is applied between the base joint and the bottom axis part that contains the drive, according to setup $2 \mathrm{~b}$ in Fig. 1.

All components of the power train contribute their stiffness to the total stiffness. For one axis, these are the base universal joint $k_{\mathrm{BJ} \text { oint }}$, the force sensor $k_{\mathrm{FSensor}}$, the drive $k_{\text {Drive }}$ that includes motor, belt drive, bearing, ball screw drive, and telescopic axle, as well as the platform universal joint $k_{\mathrm{PJoint}}$. As accuracy for hexapod parallel kinematics is mainly determined by longitudinal axis deviations and the main goal is to evaluate the stiffness change after force sensor integration, the stiffness is evaluated in longitudinal direction only, which leads to an axis stiffness $k_{\text {Axis }}$ of

$$
k_{\text {Axis }}=\left(k_{\text {BJoint }}^{-1}+k_{\text {FSensor }}^{-1}+k_{\text {Drive }}^{-1}+k_{\text {PJoint }}^{-1}\right)^{-1}
$$


The sensor integration is evaluated in comparison to an improvement of joint design, where two types of joints are mounted: cost efficient standard universal joints with crossed Cardan axes and simple bearings, and joints with eccentric Cardan axes, a stable cross shaft and backlash-free needle bearings [14-16].
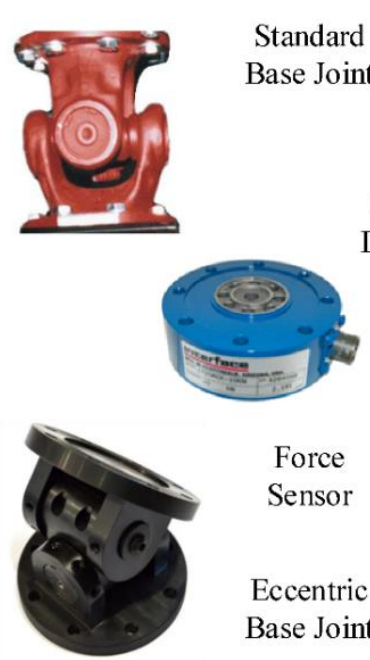

Force

Sensor

Eccentric Base Joint

Standard

Base Joint

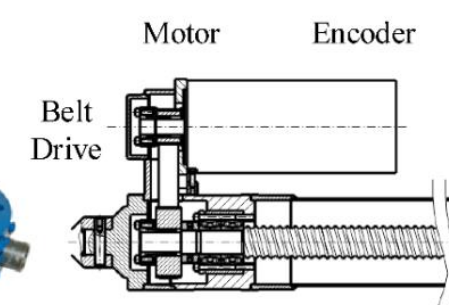

Drive Housing
+Bearing

Ball
Screw
Drive

Nut

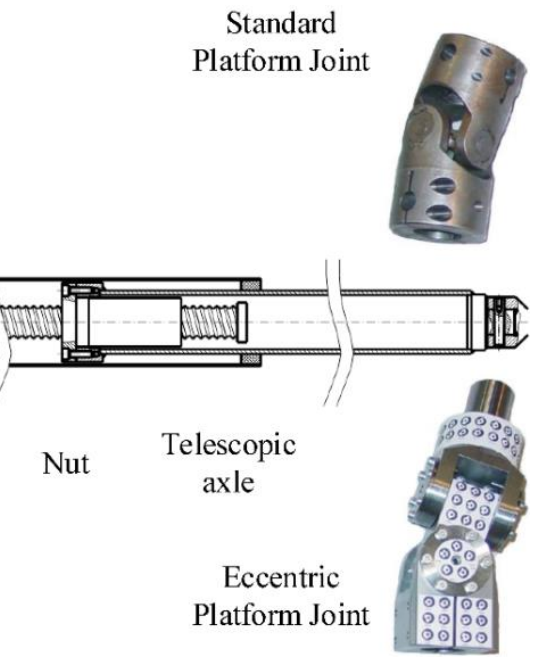

Fig. 2. Components of a hexapod strut; top: former configuration using standard universal joints, bottom: new configuration using eccentric universal joints and force sensor mounted between drive housing and base joint (setup 2b)

For experiments, an axis is disassembled from the hexapod and placed on a linear test bench, Fig. 3. Here, the base joint is fixed, Fig. 3 right, and the platform joint mounted to a linear guide, Fig. 3 left. The force is applied by a tensioning screw (not displayed) in a range of $\pm 5 \mathrm{kN}$ and measured by a separate load cell at the tension screw because the integrated force sensor is not present in all setups.
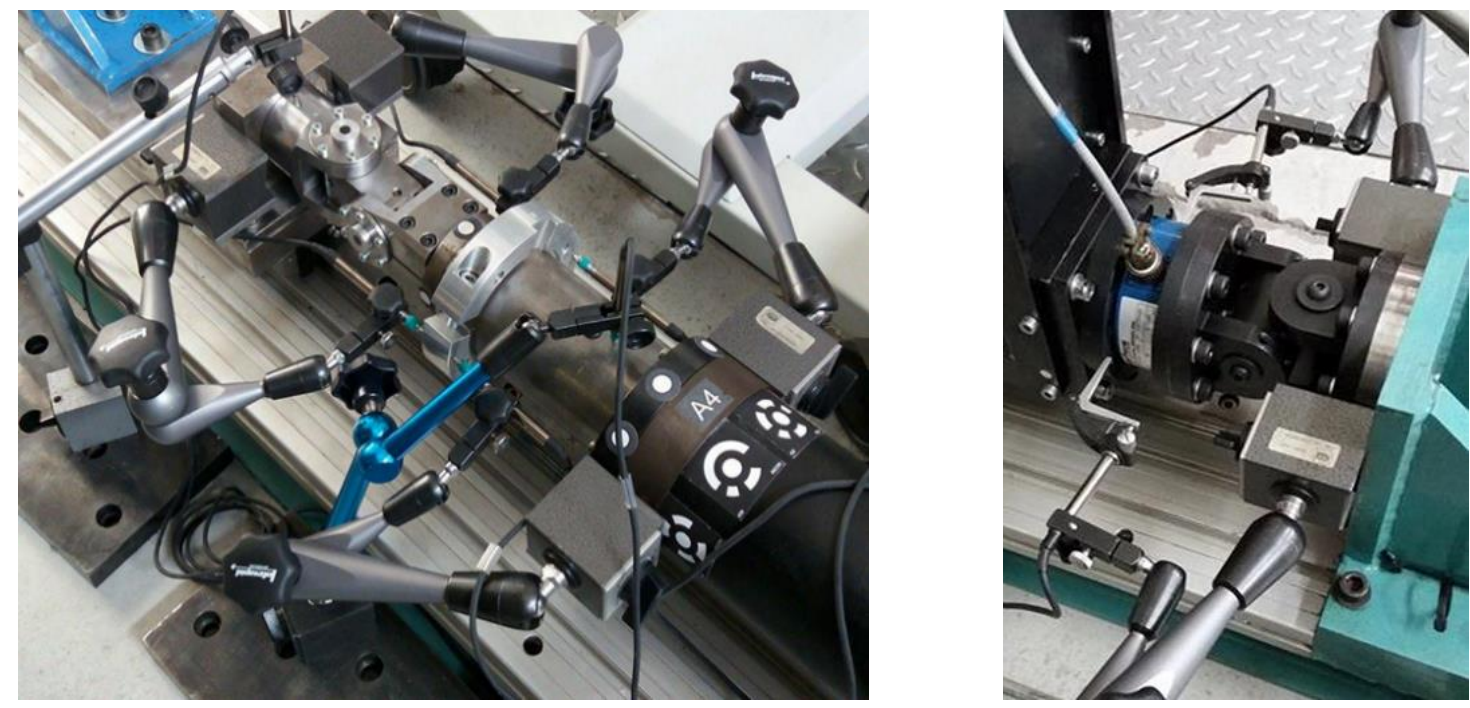

Fig. 3. Experimental setup using linear measuring probes; left: displacement measurement of drive and eccentric universal platform joint, right: displacement measurement of eccentric base joint with force sensor 
Multiple length measuring probes are applied in different positions to examine the displacement of base joint, force sensor, drive, and upper joint as well as angle changes lateral to the guiding direction. Measurements were performed for two axes in two positions each (extended, retracted) using standard and eccentric universal joints, and with assembled and disassembled force sensor. Every measurement is repeated 3 times and averaged. Displacements of opposite length probes are averaged to eliminate angle errors.

At first, the measurements result in several compliance characteristics for the components. Exemplarily, Fig. 4 presents the compliance curves of the universal joints in standard and eccentric edition for the base joints (left) and the platform joints (right). Further, it shows the compliance of the eccentric base joint with and without force sensor attached. Where the joint replacement lead to a massive reduction of compliance, hysteresis, and nonlinearity of the hexapod strut, a force sensor integration increases compliance and hysteresis.
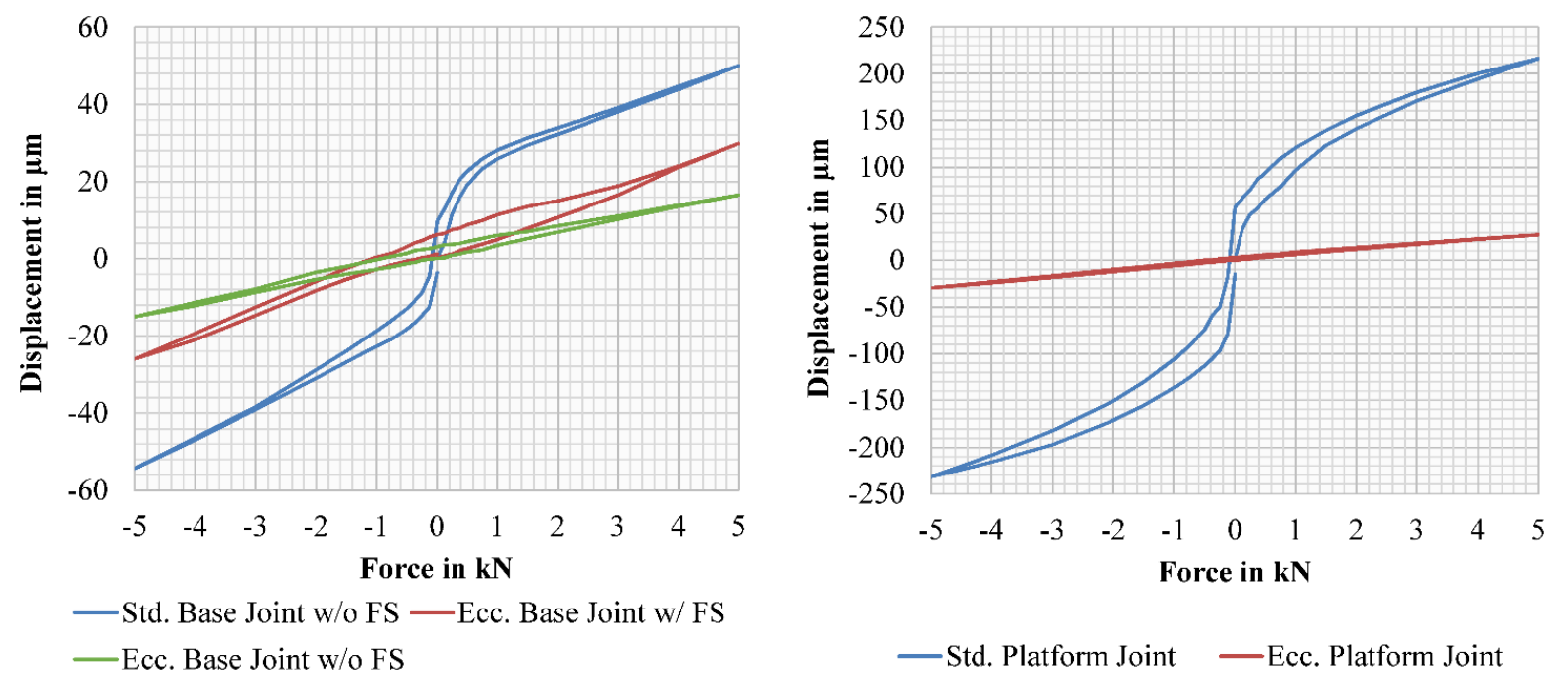

Fig. 4. Measured compliance curves; left: characteristics of eccentric base joint with and without mounted force sensor in comparison to former standard joint w/o force sensor, right: comparison of platform joints (note the different scale)

Further results are obtained by extracting the stiffness value of each component by linear regression, whereby all repetitive measurements and both evaluated hexapod struts with equal configuration are averaged. Fig. 5 shows the stiffness of the force sensor in comparison to standard and eccentric joints, and the stiffness of the drive (retracted, extended) as well as for a complete strut with and without force sensors for the former and new joint configuration.

First, it can be noted that the measured stiffness of the force sensor Interface $172010 \mathrm{kN}$ approximately matches the stiffness mentioned in the datasheet $(357 \mathrm{~N} / \mu \mathrm{m})$ and the found stiffnesses of the platform joints approximately matches the results found by photogrammetric measurements in [22] (ecc. joint $150 \mathrm{~N} / \mu \mathrm{m}$, std. joint $45 \mathrm{~N} / \mu \mathrm{m}$ ) within the range of exemplary deviations. For the base joints, a comparative study is not available.

Further, it is clearly visible that the force sensor is the stiffest part of the axis, even after joint replacement. Nevertheless, on the interpretation of Fig. 5 the behaviour of stiffness needs to be kept in mind, meaning that two springs with the same stiffness in a row result in halving the total stiffness, Eq. (1). However, in this case the force sensor integration reduces the axis 
stiffness only by approx. 5\% for standard joints and approx. $10 \%$ for eccentric joints, respectively. On the other hand, the replacement of the joints results in double stiffness of the base joint, 5 times higher stiffness of the platform joint and 2.2 times higher stiffness for the complete strut.

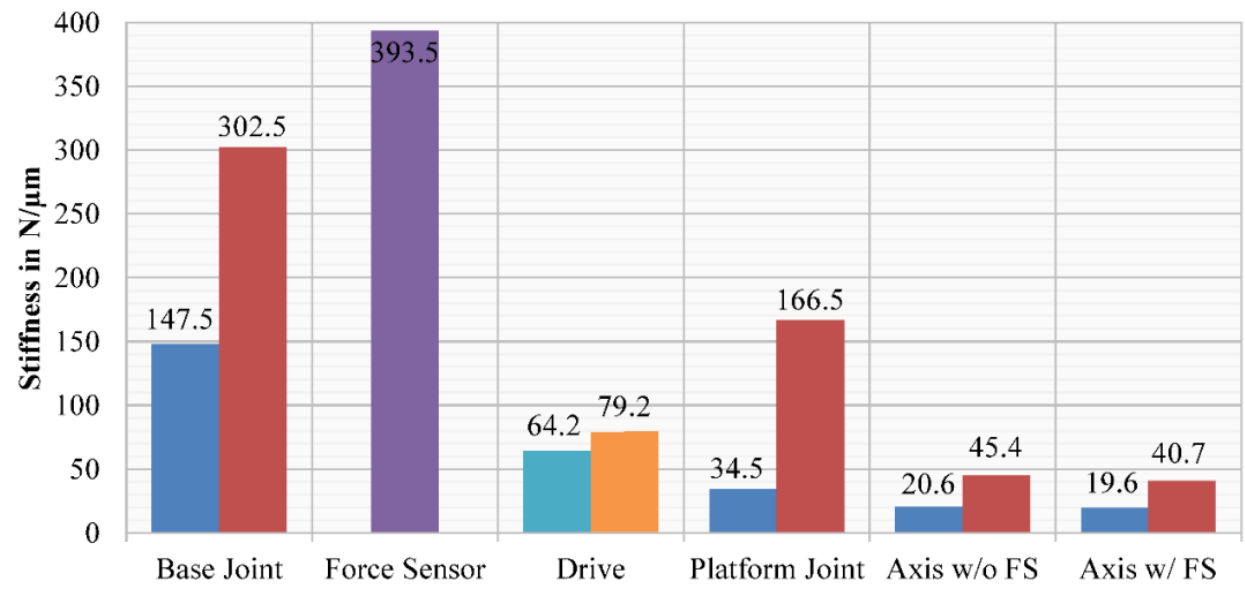

Fig. 5. Averaged component stiffnesses from two independent axis examinations: Base joints (left/blue: former configuration with standard joints, right/red: new configuration with eccentric joints), Force Sensor, Drive (left/cyan:

axis retracted, right/orange: axis extended), Platform joints, and complete axis without and with force sensor

An even better view on the composition of the strut stiffness gives the compliance bar graph, where component compliances sum up to the total axis compliance, Fig. 6. It identifies the platform joint as main influence of stiffness loss for the standard joints and the drives as main influence for the eccentric joint configuration. This means that if stiffness shall be increased further, the preferred component to concern is the drive train but rather not the force sensor itself.

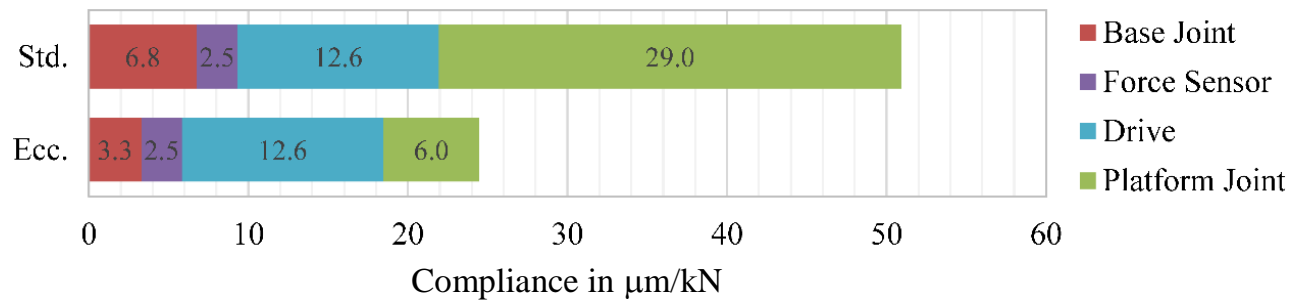

Fig. 6. Components of compliance for a hexapod strut including force sensor; top: standard universal joints with force sensor, bottom: eccentric universal joints with force sensor

As first conclusion, even though force sensors normally have high stiffness, high linearity by design and small hysteresis, a force sensor integration always reduces the stiffness of a system, when relating to the rules of stiffness series connection. Nevertheless, this statement needs to be reflected upon the other components of the system. In many cases, especially for kinematics, the force sensor will be the stiffest component in a setup and if higher stiffness is required, other components, such as joints or drive train, need to be improved first. In the present case, after improving joint design, the axis stiffness with force 
sensor and eccentric joints has twice the stiffness of the former configuration with standard joints without force sensor.

\section{MACHINE STIFFNESS EVALUATION}

In the next step, the stiffness change due to axis sensor integration (2b) is evaluated for the complete machine tool. In addition, the effect of a force sensor integration into the endeffector platform (1b) is investigated. Again, the results are compared to the stiffness change resulting from the joint improvement.

For experiments, the hexapod machine tool is assembled in four configurations: standard and eccentric universal joints without force sensors, eccentric universal joints with force sensors in the end-effector platform (see Fig. 1 setup 1b, 6x ALTHEN F256 $5 \mathrm{kN}, 78$ N/ $\mu \mathrm{m}$ ), and eccentric universal joints with force sensors in the struts (see Fig. 1 setup 2b, 6x INTERFACE $172010 \mathrm{kN}, 357 \mathrm{~N} / \mu \mathrm{m}$ ). With each setup, seven double ball bar (DBB) measurements are performed subsequently in the $X Y, X Z$, and $Y Z$ plane with loads of $0 \mathrm{~kg}$, $50 \mathrm{~kg}, 100 \mathrm{~kg}, 150 \mathrm{~kg}, 100 \mathrm{~kg}, 50 \mathrm{~kg}$, and $0 \mathrm{~kg}$ (Fig. 7). Thereby, $0 \mathrm{~kg}$ is the reference value for deflection analysis and the repetitive load situations, performed with equal distance of time, are used to eliminate thermal effects from the data.

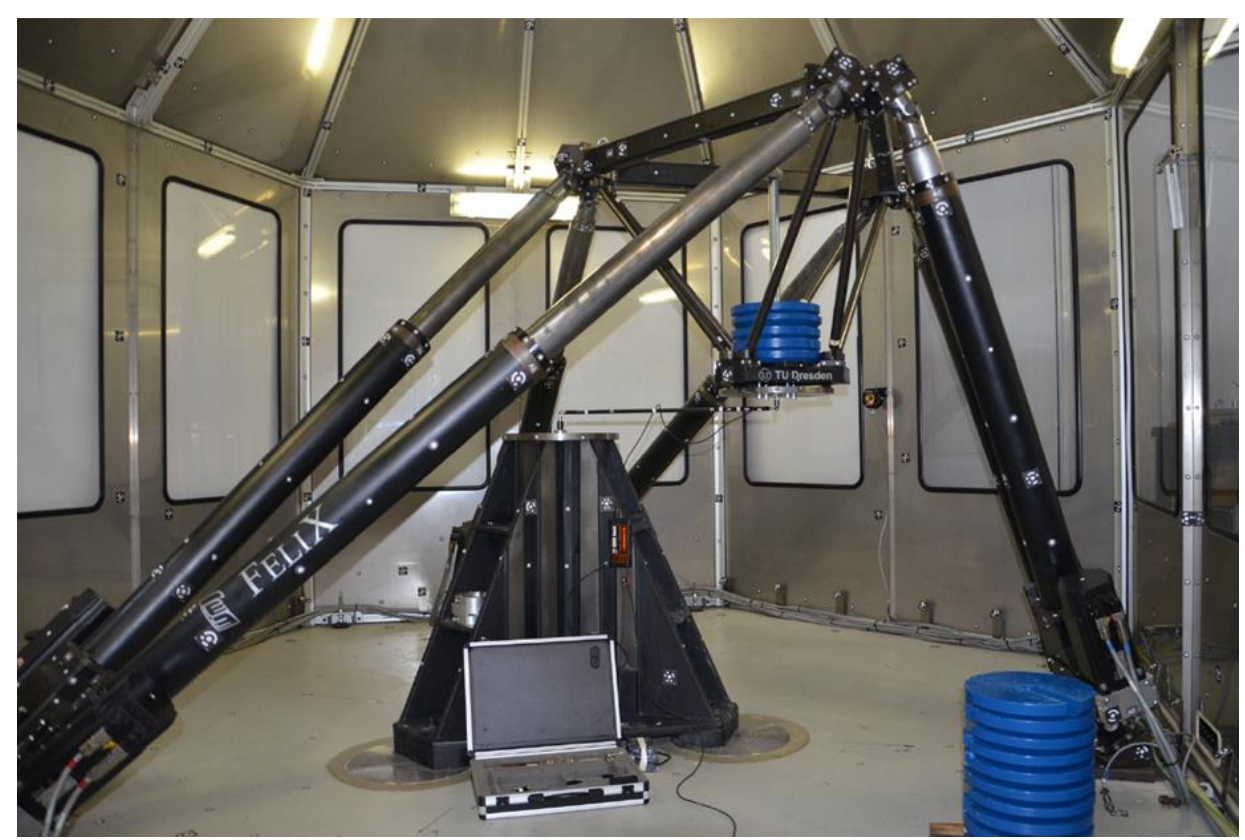

Fig. 7. Compliance evaluation of hexapod machine tool FELIX by the use of the double-ball-bar measuring system

While the load direction is constantly set to $-Z$ by gravity, the direction of the displacement measurement changes with the direction of the DBB (Renishaw QC 10, $\pm 1 \mathrm{~mm}$ range, $\pm 0.1 \mu \mathrm{m}$ resolution). At the same time, the displacement is acquired at constantly changing positions within the workspace. Even though, these circumstances prevent calculating specific compliance values in large parts, the experiment is perfectly suitable to 
evaluate stiffness changes related to configuration changes in the whole workspace qualitatively, as shown in Fig. 8. The plots present the displacements as deviation relative to the "zero circle" (fat black circle) with a radial scale of $10 \mu \mathrm{m}$ per tick for loads of $50 \mathrm{~kg}$ (blue), $100 \mathrm{~kg}$ (green) and $150 \mathrm{~kg}$ (red). Compared to the dashed reference configuration that is eccentric joints without force sensors, the effects of standard joint and force sensor integration becomes visible: sensor integration slightly reduces stiffness, but does not bring significant non-linearity for both setups. In contrast to this, beside the loss of stiffness when using standard joints, also their strong non-linear behaviour appear.

Std. Joints w/o FS

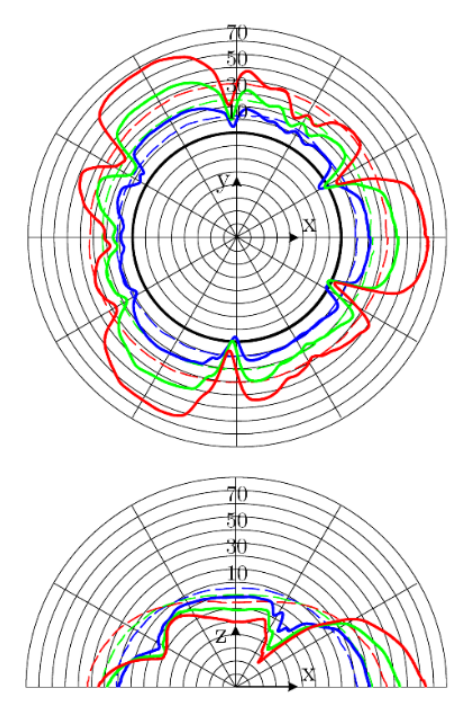

Ecc. Joints with Platform Force Sensors (1b)
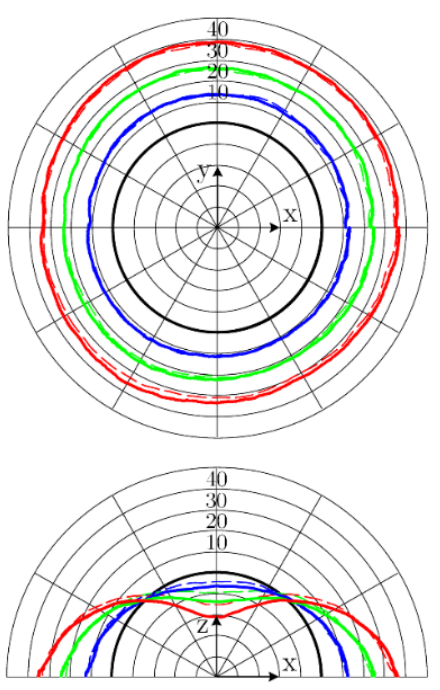

Ecc. Joints with Strut Force Sensors (2b)
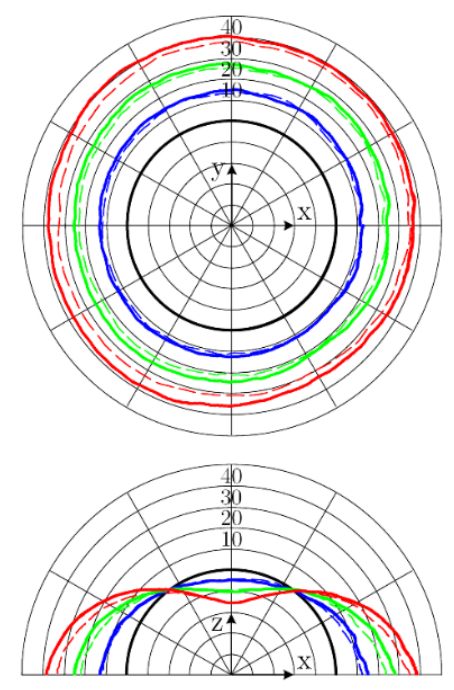

Fig. 8. Elastic deflection of the TCP (radial ticks of $10 \mu \mathrm{m})$ from circular DBB measurements $(\mathrm{R}=650 \mathrm{~mm})$ in $X Y$-plane (top) and $X Z$-plane (bottom) when comparing standard joints without force sensor, eccentric joints with force sensors in the end-effector platform (setup 1b) and eccentric joints with force sensors in the struts (setup 2b) to eccentric joints without force sensors (dashed line) for loads of $50 \mathrm{~kg}$ (blue), $100 \mathrm{~kg}$ (green) and $150 \mathrm{~kg}$ (red)

Since the rigid platform is not inclined during the DBB measurements, no lateral forces to the platform sensors are induced and significant displacements appear mainly in $Z$-direction. For the strut sensors, the displacements in all directions are meaningful, as for the kinematic sufficient load changes result already from position changes (no inclination required).

The plots also allow extracting some characteristics, such as the "roundness error" presented in Table 1 that in this case represents the range of displacement along the circle for the specific load situation. Particularly, when comparing the changed systems to the reference setup containing eccentric joints w/o force sensors, setup $2 b$ lead to the smallest stiffness change ahead of setup $1 \mathrm{~b}$, and the configuration using standard eccentric joints.

At specific points in the workspace, where the DBB measuring direction is collinear to a coordinate axis, it is possible to extract specific compliance values, which are inverted to stiffness values and presented in Table 1, lower part. For standard joints, the values are extracted from a fitted circle due to their non-linearity. For the other setups, averages are taken of 6 repeated measurements. 
Table 1. Specific exemplary characteristics extracted from DBB measurement circles of Fig. 8

\begin{tabular}{|c|c|c|c|c|}
\hline $\begin{array}{c}\text { Roundness error of } \\
\text { circle for load of } \\
150 \mathrm{~kg}\end{array}$ & $\begin{array}{c}\text { Std. Joints w/o } \\
\text { Force Sensors }\end{array}$ & $\begin{array}{c}\text { Ecc. Joints w/o Force } \\
\text { Sensors }\end{array}$ & $\begin{array}{c}\text { Ecc. Joints with } \\
\text { Platform Force } \\
\text { Sensors (1b) }\end{array}$ & $\begin{array}{c}\text { Ecc. Joints with Strut } \\
\text { Force Sensors (2b) }\end{array}$ \\
\hline$X Y$ & $63.3 \mu \mathrm{m}$ & $3.7 \mu \mathrm{m}$ & $4.8 \mu \mathrm{m}$ & $4.4 \mu \mathrm{m}$ \\
\hline$X Z$ & $113.2 \mu \mathrm{m}$ & $50.7 \mu \mathrm{m}$ & $57.1 \mu \mathrm{m}$ & $55.1 \mu \mathrm{m}$ \\
\hline$Y Z$ & $69.7 \mu \mathrm{m}$ & $50.1 \mu \mathrm{m}$ & $57.9 \mu \mathrm{m}$ & $54.1 \mu \mathrm{m}$ \\
\hline
\end{tabular}

\begin{tabular}{|c|c|c|c|c|}
\hline $\begin{array}{c}\text { Stiffness component } \\
\text { at position }(X, Y, Z)\end{array}$ & $\begin{array}{c}\text { Std. Joints w/o } \\
\text { Force Sensors }\end{array}$ & $\begin{array}{c}\text { Ecc. Joints w/o Force } \\
\text { Sensors }\end{array}$ & $\begin{array}{c}\text { Ecc. Joints with } \\
\text { Platform Force } \\
\text { Sensors (1b) }\end{array}$ & $\begin{array}{c}\text { Ecc. Joints with } \\
\text { Strut Force Sensors } \\
(2 \mathrm{~b})\end{array}$ \\
\hline$k_{Z X}( \pm 650,0, \mathrm{M})$ & $\sim 34.6 \mathrm{~N} / \mu \mathrm{m}$ & $42.3 \pm 1.8 \mathrm{~N} / \mu \mathrm{m}$ & $40.5 \pm 2.3 \mathrm{~N} / \mu \mathrm{m}$ & $38.2 \pm 1.2 \mathrm{~N} / \mu \mathrm{m}$ \\
\hline$k_{Z Y}(0, \pm 650, \mathrm{M})$ & $\sim 34.6 \mathrm{~N} / \mu \mathrm{m}$ & $40.9 \pm 1.4 \mathrm{~N} / \mu \mathrm{m}$ & $39.9 \pm 1.9 \mathrm{~N} / \mu \mathrm{m}$ & $37.3 \pm 1.2 \mathrm{~N} / \mu \mathrm{m}$ \\
\hline$k_{Z Z}(0,0, \mathrm{M}+650)$ & $\sim 46.6 \mathrm{~N} / \mu \mathrm{m}$ & $102.1 \pm 9.1 \mathrm{~N} / \mu \mathrm{m}$ & $71.7 \pm 6.6 \mathrm{~N} / \mu \mathrm{m}$ & $100.3 \pm 7.7 \mathrm{~N} / \mu \mathrm{m}$ \\
\hline & \multicolumn{3}{|c|}{ Loss of stiffness when compared to Ecc. Joints w/o FS } \\
\hline$k_{Z X}( \pm 650,0, \mathrm{M})$ & $-18.2 \%$ & - & $-4.3 \%$ & $-9.8 \%$ \\
\hline$k_{Z Y}(0, \pm 650, \mathrm{M})$ & $-15.4 \%$ & - & $-2.6 \%$ & $-8.9 \%$ \\
\hline$k_{Z Z}(0,0, \mathrm{M}+650)$ & $-54.4 \%$ & - & $-29.7 \%$ & $-1.7 \%$ \\
\hline
\end{tabular}

Again, the loss of stiffness for strut force sensor integration (2b) is less than $10 \%$, which validates the results presented above. Platform sensor integration (1b) instead, shows a significant loss of stiffness in the main and representative direction $k_{Z Z}$. In this case, force sensors are integrated into a rigid steel structure with a stiffness for one bar of $210 \mathrm{~N} / \mu \mathrm{m}$ $\left(k_{\mathrm{PFBar}}=\frac{E A}{l}, D=28 \mathrm{~mm}, l=613 \mathrm{~mm}\right)$, which is much higher than a sensors stiffness of $78 \mathrm{~N} / \mu \mathrm{m}$. Here, a loss of stiffness is impossible to avoid. Even when considering different sensors, which are available with a stiffness until $230 \mathrm{~N} / \mu \mathrm{m}$, and regarding gaps and screws of the structure, the total loss of stiffness by sensor integration will be significant.

At this point, it shall be noted that also the integration of a commercial $6 \mathrm{DoF}$ force/torque sensor at the end-effector reduces machine stiffness. To quantify these effects, a simple theoretical stiffness calculation using Eq. (2) can be performed for a hexapod with several sensor configurations, where the used commercial F/T-sensor is an ATI OMEGA 190 with $\left.\boldsymbol{K}_{\mathrm{FT}}=\left(\begin{array}{ll}250250370 \mid 1.61 .63 .0\end{array}\right) \mathrm{N} / \mu \mathrm{m} \mid \mathrm{Nm} / \mu \mathrm{rad}\right)$. First, for parallel connection, bar or axis stiffnesses calculate to the total Cartesian stiffness as following $\boldsymbol{K}_{x}=\boldsymbol{J}^{-T} \boldsymbol{K}_{\text {Axis }} \boldsymbol{J}^{-1}$, with the help of the Jacobian $\boldsymbol{J}$ and $\boldsymbol{K}_{\text {Axis }}$ that is a diagonal matrix including the bar/axes stiffnesses [25]. Taking the constant Jacobian of the end-effector platform $\boldsymbol{J}_{P}$ from [4] and the pose-dependent Jacobian of the Hexapod $\boldsymbol{J}_{\mathrm{Hex}}(\boldsymbol{x})$ from [13], and combining them with the end-effector in serial connection lead to the total pose-dependent stiffness of the hexapod machine tool.

$$
\boldsymbol{K}_{\mathrm{Hex}}(\boldsymbol{x})=\left(\left[\boldsymbol{J}_{\mathrm{Hex}}^{-T}(\boldsymbol{x}) \boldsymbol{K}_{\mathrm{Axis}} \boldsymbol{J}_{\mathrm{Hex}}^{-1}(\boldsymbol{x})\right]^{-1}+\left[\boldsymbol{J}_{P}^{-T} \boldsymbol{K}_{\mathrm{PFBar}} \boldsymbol{J}_{P}^{-1}\right]^{-1}+\left[\boldsymbol{K}_{F T}\right]^{-1}\right)^{-1}
$$

Table 2 presents the calculated main diagonal elements of the resulting stiffness matrices. The calculation neglects the stiffness of the platform part above the bars that is unknown but equal for all setups, which explains higher calculated stiffness values when 
compared to the measurement presented above. However, the stiffness changes are in the same range as the measurements.

Table 2. Calculated main diagonal stiffness components in $\mathrm{N} / \mu \mathrm{m}$ and $\mathrm{Nm} / \mu \mathrm{rad}$ of a complete hexapod machine tool using eccentric joints in home position for different solutions of force sensor integration

\begin{tabular}{|l|c|c|c|c|c|c|}
\hline Hexapod stiffness at TCP N/ $\mu \mathrm{m} \mid \mathrm{Nm} / \mu \mathrm{rad}$ & $\mathrm{K}_{X X}$ & $\mathrm{~K}_{Y Y}$ & $\mathrm{~K}_{Z Z}$ & $\mathrm{~K}_{A A}$ & $\mathrm{~K}_{B B}$ & $\mathrm{~K}_{C C}$ \\
\hline $\begin{array}{l}\text { w/o force sensors } \\
k_{\text {Axis }}=45.4 \mathrm{~N} / \mu \mathrm{m}, k_{\mathrm{PFBar}}=210 \mathrm{~N} / \mu \mathrm{m}\end{array}$ & 19.4 & 19.4 & 149.7 & 6.7 & 6.7 & 7.0 \\
\hline $\begin{array}{l}\text { Force } / \text { torque sensor }(\mathrm{R}) \\
k_{\text {Axis }}=45.4 \mathrm{~N} / \mu \mathrm{m}, k_{\mathrm{PFBar}}=210 \mathrm{~N} / \mu \mathrm{m} \\
\left.K_{\mathrm{FT}}=(250250370 \mid 1.61 .63 .0) \mathrm{N} / \mu \mathrm{m} \mid \mathrm{Nm} / \mu \mathrm{rad}\right)\end{array}$ & 17.6 & 17.6 & 106.6 & 4.7 & 5.8 & 5.7 \\
\hline $\begin{array}{l}\text { Platform force sensors type } 178 \mathrm{~N} / \mu \mathrm{m}(1 \mathrm{~b}) \\
k_{\text {Axis }}=45.4 \mathrm{~N} / \mu \mathrm{m}, k_{\mathrm{PFBar}}=59 \mathrm{~N} / \mu \mathrm{m}\end{array}$ & 15.0 & 15.0 & 100.7 & 2.0 & 3.0 & 2.4 \\
\hline $\begin{array}{l}\text { Platform force sensors type } 2230 \mathrm{~N} / \mu \mathrm{m}(1 \mathrm{~b}) \\
k_{\text {Axis }}=45.4 \mathrm{~N} / \mu \mathrm{m}, k_{\mathrm{PFBar}}=118 \mathrm{~N} / \mu \mathrm{m}\end{array}$ & 17.5 & 17.5 & 130.4 & 3.9 & 3.9 & 4.4 \\
\hline $\begin{array}{l}\text { Strut force sensors } 357 \mathrm{~N} / \mu \mathrm{m}(2 \mathrm{~b}) \\
k_{\text {Axis }}=40.7 \mathrm{~N} / \mu \mathrm{m}, k_{\mathrm{PFBar}}=210 \mathrm{~N} / \mu \mathrm{m}\end{array}$ & 17.8 & 17.8 & 136.9 & 6.6 & 6.6 & 6.8 \\
\hline
\end{tabular}

Table 2 shows that even a force/torque sensor with high stiffness mounted at the endeffector reduces the machine stiffness significantly and in the presented case more than the sensor integration solution $2 \mathrm{~b}$. Especially, when regarding the mentioned better sensor for setup $1 \mathrm{~b}$, also the setup $1 \mathrm{~b}$ can reach competitive characteristics for translational directions, when compared to a force/torque sensor mounted at the end-effector. In consequence, as the achievable stiffness for a single force sensor is limited, a sensor combination of six singleaxis parallel-connected sensors can be advantageous to one $6 \mathrm{DoF}$ sensor with the same stiffness in serial connection to the end-effector.

\section{CONCLUSION}

In general, a strain-gauge-based force sensor can be regarded as a spring that, when integrated into a machine tool, always reduces the total stiffness. Especially, when integrating force sensors in rigid structural components that already have high stiffness, a loss of stiffness is hard to avoid. On the other hand, force sensors usually have high stiffness, high linearity, and small hysteresis by design, in contrast to many other parts, such as drive train or joints, in a mechanical system. Therefore, the resulting grade of stiffness reduction depends on the stiffness and number of other compliant components in the system, in particular when the components are mounted in series connection. In case of the presented hexapod strut, the force sensor is the stiffest of five parts in a row and therefore the loss of stiffness caused by the sensor integration is acceptable with 5\% (standard joints) and 10\% (eccentric joints), respectively. When compared to an improvement of joint design, the resulting total axis stiffness with force sensor and new eccentric joints is twice the stiffness of the former configuration with standard joints and without force sensor. In other words, if a systems stiffness is important, the weakest part needs to be improved first. Therefore, 
a general strategy for force sensor integration should contain a detailed analysis of the structure and all compliant components in the system, a selection of sensors with high stiffness when compared to other components, and a priority for parallel circuits if applicable. Then, in many cases a force sensor integration can be realised without significant loss of stiffness. Consequently, the results support the approach of structure-integrated force measurement for parallel kinematics, give a guideline for sensor integration, and can be used for applications that need stiffness information, such as force control.

\section{ACKNOWLEDGEMENTS}

The authors are grateful to the German Research Foundation (DFG) who supported this work with the projects "Fundamentals for structure-integrated measurement and control-integrated processing of spatial forces and torques in machine tools" (DFG No 202081830) and "Fundamentals for the use of eccentric joints in parallel kinematic machine tools" (DFG No 53530748). Further, the authors want to thank the editors and reviewers for their helpful comments and constructive suggestions with regard to the revision of this paper.

\section{REFERENCES}

[1] ALTINTAS Y., PARK S., 2004, Dynamic Compensation of Spindle-Integrated Force Sensors, CIRP Annals Manufacturing Technology, 53/1, 305-308.

[2] HESSELBACH J., BEHRENS B.A., DIETRICH F., POELMEYER J., RATHMANN S., 2008, Regelunskonzept für eine Umformmaschine auf Basis einer Parallelstruktur und simulative Ermittlung von prozessgerechten Maschinenparametern, Fertigungsmaschinen mit Parallelkinematiken, Shaker Verlag, 307-322.

[3] DENKENA B., DAHLMANN D., BOUJNAH H., 2016, Sensory Workpieces for Process Monitoring - An Approach, Procedia Technology, 26, 129-135.

[4] FRIEDRICH C., KAUSCHINGER B., IHLENFELDT S., 2019, Spatial force measurement using a rigid hexapodbased end-effector with structure-integrated force sensors in a hexapod parallel kinematic, Measurement, 145C, 350-360.

[5] DESOGUS S., GERMAK A., MAZZOLENI F., QUAGLIOTTI D., BARBATO G., BARBIERI A., BIGOLIN G., BIN C., 2010, Developing multicomponent force transducers at INRiM, IMEKO World Congress, 17-19.

[6] GENTA G., GERMAK A., BARBATO G., LEVI R., 2016, Metrological characterization of an hexapod-shaped Multicomponent Force Transducer, Measurement, 78, 202-206.

[7] KANG C.-G., 2001, Closed-form force sensing of a 6-axis force transducer based on the Stewart platform, Sensors and Actuators A: Physical, 90/1, 31-37.

[8] NITSCHE J., BAUMGARTEN S., PETZ M., RÖSKE D., KUMME R., TUTSCH R., 2017, Measurement uncertainty evaluation of a hexapod-structured calibration device for multi-component force and moment sensors, Metrologia, 54/2, 171-183.

[9] OELHYDRAULIK HAGENBUCH AG, 2017, Kräfte messen mit Hexamove-Konzept, Produktprospekt: Hexamove - Bewegung leichtgemacht, 16, 17-17.

[10] PALUMBO S., GERMAK A., MAZZOLENI F., DESOGUS S., BARBATO G., 2016, Design and metrological evaluation of the new 5 MN hexapod-shaped multicomponent build-up system, Metrologia, 53/3, 956-964.

[11] RÖSKE D., 2003, Metrological characterization of a hexapod for a multi-component calibration device, XVII IMEKO World Congress (Metrology in the 3rd millennium), 347-351.

[12] SEIBOLD U.S., 2013, An advanced force feedback tool design for minimally invasive robotic surgery, PhD thesis, Technische Universität München.

[13] FRIEDRICH C., KAUSCHINGER B., IHLENFELDT S., 2016, Decentralized structure-integrated spatial force measurement in machine tools, Mechatronics, 40, 17-27.

[14] KAUSCHINGER B., 2006, Verbesserung der Bewegungsgenauigkeit an einer Parallelkinematik einfacher Bauart, PhD thesis, TU Dresden.

[15] ARCHENTI A., NICOLESCU M., CASTERMAN G., HJELM S., 2012, A new method for circular testing of machine tools under loaded condition, Procedia CIRP, 1, 575-580. 
[16] FRINDT M., 2001, Modulbasierte Synthese von Parallelstrukturen für Maschinen in der Produktionstechnik, PhD thesis, TU Braunschweig.

[17] KREFFT M., 2006, Aufgabenangepasste Optimierung von Parallelstrukturen für Maschinen in der Produktionstechnik, PhD thesis, TU Braunschweig.

[18] MERLET J.P., 2006, Parallel robots, 128. Springer Science \& Business Media.

[19] CARBONE G., 2011, Stiffness analysis and experimental validation of robotic systems, Frontiers of Mechanical Engineering, 6/2, 182-196.

[20] NEUGEBAUER R. editor, 2006, Parallelkinematische Maschinen: Entwurf, Konstruktion, Anwendung, VDI-Buch, Springer.

[21] RUDOLPH H., 2012, Ein Beitrag zur Analyse der nichtlinearen Systemdynamik in der Entwurfsphase von Werkzeugmaschinen, PhD thesis, TU Dresden.

[22] GROSSMANN K., KAUSCHINGER B., RIEDEL M., 2013, Optische Verlagerungsmessung an Kardangelenken, WT Online, 103, 402-409.

[23] GROSSMANN K., KAUSCHINGER B., RIEDEL M., 2012, Exzentrische Gelenke für parallelkinematische Werkzeugmaschinen, ZWF, 01-02, 25-32.

[24] GROSSMANN K., KAUSCHINGER B., 2012, Eccentric universal joints for parallel kinematic machine tools: variants and kinematic transformations, Production Engineering, 6/4-5, 521-529.

[25] CHEN S.F., KAO I., 2000, Conservative Congruence Transformation for Joint and Cartesian Stiffness Matrices of Robotic Hands and Fingers, The International Journal of Robotics Research, 19/9, 835-847. 